\title{
Physical activity during pregnancy in a prospective cohort of British women: results from the Avon longitudinal study of parents and children
}

\author{
Jihong Liu $\cdot$ Steven N. Blair $\cdot$ Yanping Teng $\cdot$ \\ Andrew R. Ness • Debbie A. Lawlor • \\ Chris Riddoch
}

Received: 12 July 2010/Accepted: 9 December 2010/Published online: 30 December 2010

(C) Springer Science+Business Media B.V. 2010

\begin{abstract}
We sought to examine the levels, types, and changes of physical activity and their correlates among pregnant women. Data came from 9,889 pregnant women with due dates between April 1, 1991 and December 31, 1992 who were participants of the Avon Longitudinal Study of Parents and Children (ALSPAC) in Bristol, Avon, Southwest England. Self-reported physical activity during pregnancy was collected via questionnaires administered at 18 and 32 weeks of gestation. We found, at 18 weeks of gestation, the prevalence of engaging in physical activity that was sufficient to cause sweating for $\geq 3 \mathrm{~h} /$ week (referred to as strenuous physical activity) was $48.8 \%$. This percentage was
\end{abstract}

Electronic supplementary material The online version of this article (doi:10.1007/s10654-010-9538-1) contains supplementary material, which is available to authorized users.

J. Liu $(\varangle) \cdot$ S. N. Blair · Y. Teng

Department of Epidemiology and Biostatistics, Arnold School

of Public Health, University of South Carolina, 800 Sumter

Street, HESC 208B, Columbia, SC 29208, USA

e-mail: Jihong.liu2003@ post.harvard.edu

\section{S. N. Blair}

Department of Exercise Science, Arnold J. Norman School

of Public Health, University of South Carolina,

Columbia, SC, USA

A. R. Ness

School of Oral and Dental Sciences, University

of Bristol, Bristol, UK

D. A. Lawlor

MRC Centre for Causal Analyses in Translational

Epidemiology, Department of Social Medicine,

University of Bristol, Bristol, UK

C. Riddoch

School for Health, University of Bath, Bath, UK similar at 32 weeks of gestation. The most common physical activity during pregnancy reported by these women was brisk walking, followed by swimming and ante-natal exercise. In models that mutually adjusted for all characteristics examined, younger women, women in lower social classes, those not employed during pregnancy, married and parous women (compared to those not in each of these groups) were more likely to report engaging in strenuous physical activity. After becoming pregnant, about two out of three of these women reported reducing physical activity levels at 18 weeks of gestation. In mutually adjusted models, women who were younger, fit and well, parous, and women from lower social classes (compared to those not in each of these groups) were less likely to report reducing their physical activity. Our findings provide insights that are relevant to the design of future observational and intervention studies concerned with the effects of physical activity during pregnancy on health outcomes for mothers and offspring.

Keywords ALSPAC - Leisure-time physical activity . Exercise $\cdot$ Swimming $\cdot$ Walking $\cdot$ Pregnancy

$\begin{array}{ll}\text { Abbreviations } \\ \text { ACOG } & \begin{array}{l}\text { American College of Obstetricians and } \\ \text { Gynecologists }\end{array} \\ \text { ALSPAC } & \begin{array}{l}\text { The Avon Longitudinal Study of Parents and } \\ \text { Children }\end{array} \\ \text { BMI } & \text { Body mass index } \\ \text { CI } & \text { Confidence interval } \\ \text { IQR } & \text { Interquartile range } \\ \text { MET } & \text { Metabolic equivalent } \\ \text { RCOG } & \text { The Royal College of Obstetricians and } \\ & \text { Gynaecologists } \\ \text { UK } & \text { United Kingdom }\end{array}$




\section{Introduction}

Physical activity has been associated with beneficial health effects in non-pregnant individuals [1-3]. In the last two decades there has been increased interest in the health effects of physical activity during pregnancy [4]. Most observational epidemiological studies have reported beneficial effects of greater levels of physical activity during pregnancy for the pregnant woman, such as a decreased risk of gestational diabetes [5-11] and preeclampsia [12-16]. However, current evidence is inconsistent on whether exercise during pregnancy is beneficial [17], harmful $[18,19]$, or neutral [20-22] for the health of the fetus. These mixed findings are likely to reflect different methods of exposure and outcome assessment, different timing during the pregnancy for exposure and outcome assessments, differences in pre-pregnancy exercise habits between the study populations, and differences in the studies' abilities to control for potential confounding factors. A Cochrane systematic review of randomized controlled trials to promote aerobic exercise during pregnancy concluded that regular aerobic exercise during pregnancy (mostly swimming, static cycling, floor exercises) appears to improve women's physical fitness, but that current evidence was insufficient to draw firm conclusions about its likely overall risks or benefits for the woman or baby [23]. The reviewers concluded that larger, better quality trials are needed before confident recommendations could be made about the benefits and risk of exercise during pregnancy. Whilst randomized controlled trials are the gold standard for causality, they may be difficult to conduct amongst pregnant women who are likely to be resistant to being 'experimented' on. Therefore, evidence from observational studies may be important.

Despite the ongoing debate and lack of clear evidence about the risk and benefit ratio of promoting increased physical activity in pregnancy [19, 23], professional societies such as the American College of Obstetricians and Gynecologists (ACOG), the Royal College of Obstetricians and Gynaecologists (RCOG), the Society of Obstetricians and Gynecologists of Canada, and Canadian Society of Exercise Physiologists, have all recommended active promotion of physical activity for pregnant women [24-26]. ACOG suggested that "in the absence of either medical or obstetric contraindications, $30 \mathrm{~min}$ or more of moderate exercise a day on most, if not all, days of the week is recommended for pregnant women"[24].

Several observational epidemiological studies have provided details on the types and amount of activity undertaken by pregnant women [13, 15, 19, 27]. However, few population-based data exist that describe in detail the frequency, duration, and type of physical activity, and how these aspects of physical activity change as pregnancy progresses. Furthermore, few studies have examined key factors associated with different types and changes in physical activity over pregnancy. Better and detailed understanding of physical activity undertaken during pregnancy and its correlates will inform the types and context within which physical activity might be promoted in randomized trials and identify the key confounding factors and nature of their associations with physical activity that need to be considered in observational epidemiology.

The objectives of this study were to: (1) describe the levels, types and changes of physical activity during pregnancy; (2) examine the individual characteristics associated with the levels, types, and change in physical activity during pregnancy.

\section{Methods}

\section{Study population}

The Avon Longitudinal Study of Parents and Children (ALSPAC) is a population-based study investigating environmental and other factors that affect the health and development of children. The study methods are described in detail elsewhere [28] and on the study website (www. alspac.bris.au.uk). In brief, all pregnant women living in the three health districts centered in Bristol, England, who had an expected delivery date between April 1, 1991 and December 31, 1992 were invited to take part in the study. Ethics approval for the study was obtained from the ALSPAC Law and Ethics Committee, the Local Research Ethics Committees, and the Institutional Review Board of the University of South Carolina.

We restricted analyses to women who had singleton live births. We included the first pregnancy only for 157 women who had two or more pregnancies during the recruitment period. Information from 4,422 women who did not respond to the questionnaires at the 18 or 32 weeks of gestation or who had missing values in physical activity variables were excluded, yielding a sample of 9,889 women for this study.

Prenatal physical activity measures

\section{Participation in strenuous physical activity}

ALSPAC has included a series of physical activity questions, which were derived by the study team and tested by Wildschut et al. [29] Information on the frequency of women's physical activity during pregnancy was collected using identical questions in both the 18 and 32-week antenatal self-administrated questionnaire. Women were 
asked "nowadays, at least once a week do you engage in any regular activity like brisk walking, gardening, housework, jogging, cycling etc., long enough to work up a sweat?" We defined these activities as strenuous on the basis that the participants were specifically asked to respond "yes" only if the activity was done to a level that induced sweating. Those who answered "Yes" were asked to report their number of hours per week spent in such an activity. Because the duration of strenuous physical activity was reported in hours not in minutes, we chose a cut-off point ( $\geq 3 \mathrm{~h}$ per week) to dichotomize women into two groups. The cut-off point is used to approximate the level of exercise at moderate intensity for $30 \mathrm{~min}$ or more a day for most days of the week recommended by ACOG for healthy pregnant women [24] and recognized by RCOG [26].

\section{Types of leisure-time physical activity and weighted activity index}

In the 18-week questionnaire (but not the 32 week questionnaire), women were also asked to report the hours per week that they currently carried out 11 types of leisuretime physical activities (see Table 2 for activities asked) and other specified physical activity. Based on this, we estimated a weighted activity index (i.e., the weekly total energy expenditure from these activities) by multiplying the published average metabolic equivalent (MET) scores for the reported activities [30] with the estimated hours per week ( 7 for " $\geq 7$ h", 4 for " $2-6$ h", 0.5 for " $<1$ h", and 0 for "never"). No further definition was provided for antenatal exercise and keep-fit exercise, thus we assigned 2.0 and 3.5 METs, respectively.

\section{Perceived changes in physical activity since pregnancy}

The 18 week (not 32 week) questionnaire also collected information from the women on their perceived changes in physical activity since becoming pregnant (yes, increased a lot/a little; no, change a little; yes, decreased a lot; yes, decreased). Thus, decreased activity levels since becoming pregnant were created (decreased/decreased a lot versus increased/change a little).

\section{Perceived physical activity levels in comparison to other women}

Both the 18 and 32 week questionnaires asked women about their subjective assessment of how active she was compared with other women of her age (much or somewhat more active, about the same, somewhat or much less active).

\section{Correlates of physical activity during pregnancy}

Based on the availability of data in ALSPAC and correlates that have been examined in the previous studies [31-34], this analysis considered the following factors as potential correlates of physical activity: women's age, education, the highest social class of the couple, women's employment status at 18 weeks, marital status at 8 weeks, smoking before pregnancy, self-reported general health status, prepregnancy body mass index (BMI) based on the woman's self-report of her pre-pregnant weight and height, and previous live births. Using the 1991 Office of Population Censuses and Surveys occupation-based classification [35], occupational social class was categorized as I, II, III non manual, III manual, IV, or V, with I being the highest (senior management or professionals such as doctors) and $\mathrm{V}$ being the lowest (unskilled manual workers) social class. ALSPAC collected information on the social class of the woman and her partner based on their current or last occupation at 32 weeks of gestation and the highest social class of the couple was used in this analysis. The categorization of these correlates was shown in Table 1.

In addition, we also considered partner's physical activity as a possible correlate because prior studies have shown that partner's physical activity levels are positively correlated among adults in general [36, 37]. To our knowledge, this relationship has not been studied among pregnant women, but we speculate that women living with an active partner would be more active during pregnancy. At 18 weeks of gestation (not 32 weeks), a separate questionnaire for the woman's partner was sent to the woman with instructions for her to ask her partner to complete this. ALSPAC did not stipulate a definition of partner, and left it to the woman to make such a decision. Thus, partners are not necessarily the biological father. But when asked if the partner that they had passed the questionnaire to was the biological father, $98 \%$ stated that they were. The partner's questionnaire used identical questions on the frequency and duration of physical activity from the women's questionnaire. ALSPAC only received the partner's responses from $75 \%$ of women at 18 weeks of gestation and there were additional missing values in partner's physical activity questions. Due to this, we only examined the bivariate association between women's and their partner's physical activity $(n=7,577)$ and did not include partner's activity in the final mutually adjusted analysis including all other correlates.

Statistical analysis

The proportions of women engaging in strenuous physical activities for $3 \mathrm{~h}$ or more per week at 18 and 32 weeks of gestation were calculated and compared using the 
Table 1 Sample characteristics, the Avon longitudinal study of parents and children (ALSPAC), United Kingdom ( $\mathrm{N}=9,889)$

\begin{tabular}{|c|c|c|c|}
\hline Characteristic & $\begin{array}{l}\text { Mean } \\
(\mathrm{SD})\end{array}$ & $\mathrm{n}$ & $\begin{array}{l}\% \text { of } \\
\text { subjects }\end{array}$ \\
\hline Age (years) & $28.0(4.8)$ & & \\
\hline$\leq 19$ & & 367 & 3.7 \\
\hline $20-24$ & & 1,778 & 17.9 \\
\hline $25-29$ & & 3,960 & 40.0 \\
\hline $30-34$ & & 2,692 & 27.2 \\
\hline$\geq 35$ & & 882 & 8.9 \\
\hline Missing & & 210 & 2.1 \\
\hline \multicolumn{4}{|l|}{ Education $^{*}$} \\
\hline A level or university degree & & 3,677 & 37.2 \\
\hline O level & & 3,484 & 35.2 \\
\hline Vocational & & 949 & 9.6 \\
\hline None or CSE & & 1,725 & 17.4 \\
\hline Missing & & 54 & 0.6 \\
\hline \multicolumn{4}{|l|}{ Highest social class of the couple } \\
\hline I (Highest) & & 1,321 & 13.4 \\
\hline II & & 4,038 & 40.8 \\
\hline III, Non-manual & & 2,453 & 24.8 \\
\hline III, Manual & & 1,201 & 12.1 \\
\hline IV and V (lowest) & & 490 & 4.9 \\
\hline Missing & & 386 & 3.9 \\
\hline \multicolumn{4}{|l|}{ Marital status at 8 weeks of pregnancy } \\
\hline Unmarried & & 2,134 & 21.6 \\
\hline Married & & 7,585 & 76.7 \\
\hline Missing & & 170 & 1.7 \\
\hline \multicolumn{4}{|l|}{ Smoking status before pregnancy } \\
\hline Yes & & 3,108 & 31.4 \\
\hline No & & 6,781 & 68.6 \\
\hline \multicolumn{4}{|l|}{$\begin{array}{l}\text { Employment status at } 18 \text { weeks of } \\
\text { pregnancy }\end{array}$} \\
\hline Employed & & 6,088 & 61.6 \\
\hline Not employed & & 3,671 & 37.2 \\
\hline Missing & & 130 & 1.3 \\
\hline \multicolumn{4}{|l|}{ Self-reported general health status } \\
\hline Always fit and well & & 3,138 & 31.7 \\
\hline Usually fit and well & & 5,919 & 59.9 \\
\hline Sometimes/often/always unwell & & 715 & 7.2 \\
\hline Missing & & 117 & 1.2 \\
\hline Pre-pregnancy body mass index $\left(\mathrm{kg} / \mathrm{m}^{2}\right)$ & $22.9(3.8)$ & & \\
\hline Underweight $(<18.5)$ & & 403 & 4.1 \\
\hline Normal weight (18.5-24.9) & & 6,710 & 67.9 \\
\hline Overweight (25.0-29.9) & & 1,360 & 13.8 \\
\hline Obese $(\geq 30)$ & & 486 & 4.9 \\
\hline Missing & & 930 & 9.4 \\
\hline \multicolumn{4}{|l|}{ Previous live births } \\
\hline 0 & & 4,384 & 44.3 \\
\hline 1 & & 3,612 & 36.5 \\
\hline
\end{tabular}

Table 1 continued

\begin{tabular}{llrc}
\hline Characteristic & $\begin{array}{l}\text { Mean } \\
\text { (SD) }\end{array}$ & $\mathrm{n}$ & $\begin{array}{l}\% \text { of } \\
\text { subjects }\end{array}$ \\
\hline$\geq 2$ & 1,714 & 17.3 \\
Missing & 179 & 1.8 \\
\hline$S D$ standard deviation & & \\
CSE certificate of secondary education & \\
$*$ A levels are generally obtained at age 18. O levels and CSE are \\
generally obtained at age 16 in UK. Thus, CSE indicated lower \\
educational attainment)
\end{tabular}

McNemar's test. Physical activity levels at 18 and 32 weeks were cross-tabulated with perceived changes in activity since pregnancy, perceived physical activity levels comparing to other women, and partner's physical activity levels to assess the associations between activity measures. The Bhapkar test was used to examine the changes in the perceived physical activity levels relative to other women at 18 and 32 weeks of gestation [38, 39]. A chi-square test was used to compare the percentage of women doing strenuous physical activity by their partner's physical activity at 18 weeks.

Multiple logistic regression models were used to examine the correlates of physical activities during pregnancy. The outcomes studied were the following: (1) engaging in 3 or more hours of strenuous physical activity per week at 18 and 32 weeks of gestation, (2) perceived decrease in activity levels after becoming pregnant, (3) being in the top quintile category of weighted activity index, and (4) participating in the two most commonlyreported physical activities (i.e., brisk walking, swimming) at 18 weeks of gestation. The Wald test was used to test for linear trend using a score variable $(1,2,3 \ldots)$ representing the categories of the exposure variables. When all potential exposures/correlates were included in the multivariable analyses the sample sizes were reduced in comparison to crude analyses with just one of the exposure variables, but they were still large ranging from 8,003 to 8,136 for each outcome. In the main multivariable analyses (Tables 4 and 5) we present the crude and mutually adjusted (for all variables examined) associations with each outcome only for the participants with complete data on all variables included in the full mutually adjusted model. This allows us to compare how associations change with adjustment for other variables and hence understand the extent to which crude associations operate through associations with other exposures. In order to examine whether exclusion of participants because of missing data on one or more exposure might have biased our findings we also undertook the crude associations with the maximal number of participants for each variable and compared these to the same associations 
in the complete data group. All analyses were performed using SAS 9.2 (SAS Institute Inc., Cary, North Carolina, USA).

\section{Results}

Sample characteristics

Participants on average were 28.0 years old (range: 15-44 years, standard deviation: 4.8 ). The majority of these women had education above ordinary level (i.e., A level/ university degree or O level, $72.4 \%$ ), came from relatively high social classes (I or II) (54.2\%), were married (76.7\%), did not smoke during pregnancy $(68.6 \%)$, and were employed at 18 weeks of pregnancy (61.6\%). Over $30 \%$ of them rated their health as "always fit and well" and nearly $60 \%$ rated themselves as "usually fit or well." Two-thirds (67.9\%) of them had normal BMI (18.5-24.9) before pregnancy and $18.7 \%$ were overweight or obese. Forty-four percent of them were pregnant with their first baby (Table 1).

Types, levels, and changes of physical activity during pregnancy

The most commonly reported leisure-time physical activity during pregnancy was brisk walking with $73.7 \%$ of women reporting spending some time per week on brisk walking and $46.2 \%$ spending at least $2 \mathrm{~h} /$ week on brisk walking. The second most commonly reported activity was swimming (41.2\%), followed by ante-natal exercise (23.8\%) and keep-fit exercise (13.1\%) (Table 2). A summary score of all leisure-time physical activity (i.e., the weighted activity index) had an estimated median of 15.2 MET hours/week with an IQR of 1.9-24.0.

At 18 weeks of gestation, $66.7 \%$ of women reported engaging in some strenuous physical activity at least once a week, while nearly half of women $(48.8 \%)$ spent 3 or more hours/week in strenuous physical activity $(95 \%$ confidence interval: 47.8-49.8). Levels of reported strenuous physical activity for these women at 32 weeks were similar to those at 18 weeks, with $66.1 \%$ of women reporting some strenuous physical activity and $48.9 \%$ reporting at least $3 \mathrm{~h} /$ week in strenuous physical activity (two-sided $P$ values for the differences between 18 and 32-week proportions $>0.2$ ) (Table 3).

Nearly three out of five women reported decreasing their physical activity somewhat or a lot after becoming pregnant. Women who reported decreasing their physical activity levels after becoming pregnant were less likely to spend at least $3 \mathrm{~h}$ per week in strenuous physical activity at both 18 and 32 weeks of gestation (Table 3).

At 18 weeks of gestation, $61.1 \%$ of women reported about the same levels of physical activity as other women of her age, $12.2 \%$ being somewhat or much less active, and $25.6 \%$ being much or somewhat more active. Women who reported that they were much or somewhat more active than their peers at 18 weeks were more likely to participate in strenuous physical activity at both 18 and 32 weeks of gestation (Table 3).

Partner's physical activity during pregnancy

Three out of four partners (75.9\%) reported engaging in strenuous physical activity at least once a week and 58.9\%

Table 2 Frequencies and types of self-reported leisure-time physical activities at 18 weeks of gestation, ALSPAC, United Kingdom $(\mathrm{N}=9,889)$

\begin{tabular}{|c|c|c|c|c|c|}
\hline Activity & $\begin{array}{l}\text { Never } \\
\mathrm{n}(\%)\end{array}$ & $\begin{array}{l}<1 \mathrm{~h} / \text { week } \\
\mathrm{n}(\%)\end{array}$ & $\begin{array}{l}2-6 \text { h/week } \\
\text { n }(\%)\end{array}$ & $\begin{array}{l}\geq 7 \mathrm{~h} / \text { week } \\
\mathrm{n}(\%)\end{array}$ & $\begin{array}{l}\text { Missing } \\
\mathrm{n}(\%)\end{array}$ \\
\hline Brisk walking & $2,465(24.9)$ & $2,722(27.5)$ & $3,780(38.2)$ & $793(8.0)$ & $129(1.3)$ \\
\hline Swimming & $5,598(56.6)$ & $3,117(31.5)$ & $953(9.6)$ & $14(0.1)$ & $207(2.1)$ \\
\hline Ante-natal exercise & $7,347(74.3)$ & $1,886(19.1)$ & $451(4.6)$ & $7(0.1)$ & $198(2.0)$ \\
\hline Keep fit exercise & $8,347(84.4)$ & $982(9.9)$ & $302(3.1)$ & $7(0.1)$ & $249(2.5)$ \\
\hline Cycling & 9,054 (91.6) & $419(4.2)$ & $158(1.6)$ & $14(0.1)$ & $244(2.5)$ \\
\hline Aerobics & $9,178(92.8)$ & $327(3.4)$ & $151(1.5)$ & $4(0.0)$ & $229(2.3)$ \\
\hline Tennis & $9,354(94.6)$ & $177(1.8)$ & $78(0.8)$ & $3(0.0)$ & $277(2.8)$ \\
\hline Yoga & $9,374(94.8)$ & $157(1.6)$ & $121(1.2)$ & $2(0.0)$ & $235(2.4)$ \\
\hline Jogging & $9,450(95.6)$ & $190(1.9)$ & $24(0.3)$ & $0(0.0)$ & $225(2.3)$ \\
\hline Weight training & $9,528(96.4)$ & $52(0.5)$ & $26(0.3)$ & $4(0.0)$ & $279(2.8)$ \\
\hline Squash & $9,598(97.1)$ & $28(0.3)$ & $16(0.2)$ & $0(0.0)$ & $247(2.5)$ \\
\hline Other exercise & $8,945(90.5)$ & $128(1.3)$ & $376(3.8)$ & $303(3.1)$ & $137(1.4)$ \\
\hline
\end{tabular}


Table 3 Associations between physical activity (PA) measures, ALSPAC, UK ( $\mathrm{N}=9,889)$

\begin{tabular}{|c|c|c|c|c|}
\hline & \multicolumn{2}{|l|}{$\mathrm{N}(\%)$} & \multicolumn{2}{|c|}{$\%$ Strenuous $\mathrm{PA} \geq 3 \mathrm{~h} /$ week } \\
\hline & 18 weeks & 32 weeks & 18 weeks & 32 weeks \\
\hline Total & $9,889(100)$ & $9,889(100)$ & $48.8^{\mathrm{a}}$ & $48.9^{\mathrm{a}}$ \\
\hline \multicolumn{5}{|c|}{ Perceived change in PA since pregnancy } \\
\hline Yes, increased a lot/a little & $633(6.4)$ & No data & 58.6 & 58.8 \\
\hline No, change a little & $3,328(33.7)$ & & 53.6 & 52.6 \\
\hline Yes, decreased a lot & $4,830(48.8)$ & & 47.3 & 47.3 \\
\hline Yes, decreased & $1,026(10.4)$ & & 34.4 & 38.8 \\
\hline Missing & $72(0.7)$ & & 41.7 & 47.2 \\
\hline \multicolumn{5}{|c|}{ Perceived PA levels relative to other pregnant women } \\
\hline Much/somewhat more active & $2,531(25.6)$ & $2,903(29.4)$ & 61.6 & 57.0 \\
\hline About the same & $6,045(61.1)$ & $5,849(59.2)$ & 46.4 & 47.4 \\
\hline Somewhat/much less active & $1,210(12.2)$ & $1,040(10.5)$ & 35.0 & 40.3 \\
\hline Missing & $103(1.1)^{\mathrm{b}}$ & $97(0.9)^{\mathrm{b}}$ & 37.9 & 44.7 \\
\hline \multicolumn{5}{|c|}{ Partner's hours in strenuous PA $(\mathrm{n}=7,577)$} \\
\hline$\geq 3 \mathrm{~h} /$ week & 4,462 (58.9) & No data & $53.2^{\mathrm{c}}$ & $52.1^{\mathrm{d}}$ \\
\hline$<3 \mathrm{~h} /$ week & $3,115(41.1)$ & & $41.6^{\mathrm{c}}$ & $43.7^{\mathrm{d}}$ \\
\hline
\end{tabular}

$I Q R$ interquartile range, $P A$ physical activity

${ }^{a}$ McNemar test was used to assess the changes in strenuous PA $\geq 3 \mathrm{~h} /$ week between 18 and 32 weeks of gestation $(P=0.74)$

b Bhapkar test was used to assess the changes in perceived PA levels relative to other pregnant women between 18 and 32 weeks of gestation $(P<0.0001)$

${ }^{\mathrm{c}, \mathrm{d}}$ Chi-square tests were used to compare the $\%$ of strenuous PA $\geq 3 \mathrm{~h} /$ week by partner's PA at 18 and 32 weeks $(P<0.0001)$

of these partners spent at least $3 \mathrm{~h} /$ week in strenuous physical activity. Women who had an active partner at 18 weeks of gestation tended to be more active at both 18 and 32 weeks of gestation than those who had a less active partner (Table 3).

Factors associated with participating in $3 \mathrm{~h}$ strenuous physical activity per week

In the crude analyses, age, education, social class, employment status, smoking status, and parity were significantly associated with participating strenuous physical activity. After adjusting for other correlates, the associations of education with participating in at least $3 \mathrm{~h}$ per week of strenuous activity at 18 weeks of gestation attenuate to the null and associations of other variables with this outcome attenuated somewhat but with some association remaining. In these mutually adjusted analyses, women younger than 35 years old, those who did not work during pregnancy, those who were married, smoked before pregnancy, and were parous (compared with women not in each of these groups), had higher odds of participating in strenuous physical activity for $3 \mathrm{~h}$ per week at both 18 and 32 weeks of gestation (Table 4). Women with higher education (A level or university degree) were less likely to engage in strenuous physical activity at 32 weeks of gestation compared to those with lower levels of education and women from higher household social classes compared to lower classes were less likely to engage in strenuous physical activity.

Factors associated with perceived decrease in physical activity since becoming pregnant

In the crude analyses, age, education, social class, smoking status, health status, BMI, and parity were significantly associated with perceived decrease in physical activity. After adjusting for other correlates, the associations of variables such as smoking and BMI with decrease in physical activity attenuate to the null and associations of all other variables with this outcome attenuated somewhat but with some association remaining. In mutually adjusted models, younger women, women who reported always being fit and well, and parous women were less likely to report a decrease in physical activity levels during pregnancy than their counterparts. Women with higher education and those in higher social classes were more likely to decrease their activity levels during pregnancy (Table 4).

Factors associated with participating in leisure-time physical activity

Table 5 presents the crude and adjusted odds ratios for being in the top quintile of weighted activity index based 
on leisure-time physical activities. In the crude analyses, education, social class, employment status, and health status were significantly associated with top quintile of weight activity index, brisk walking and swimming. After adjusting for other correlates, the association of social class with brisk walking and top quintile of weighted activity index were attenuated to the null while social class remains significantly associated with swimming. The associations of other variables (i.e., education, health status) with the outcomes in leisure time activity attenuated somewhat but with some association remaining. Interestingly the associations between age, employment and leisure time physical activity were strengthened or became significant after adjusting for other correlates. Younger women, women with higher level of education, those who did not work during pregnancy, and those who reported always being fit and well, were more likely to be in the top quintile group for weighted activity index. Women aged 25-34, those with higher education, who did not work during pregnancy, and those who reported being fit and healthy during pregnancy had higher odds of reporting brisk walking during pregnancy. Women who were obese before pregnancy had lower odds of report brisk walking than normal weight women. Women younger than 35 years old, those with higher education, in higher social classes, who did not smoke before pregnancy, and parous women had higher odds of reporting swimming during pregnancy.

\section{Sensitivity analyses}

Web-Table 1 shows the crude odds ratios for each exposure with each outcome with maximal numbers (i.e. without restricting to those who have complete data on all covariables for each outcome). It shows that these odds ratios are very similar to the equivalent crude odds ratios based on complete case analyses presented in Tables 4 and 5 .

\section{Discussion and conclusions}

We found that nearly two-thirds of ALSPAC pregnant women reported reducing their activity levels since becoming pregnant. About half of the women engaged in strenuous physical activity for $3 \mathrm{~h}$ or more per week and this proportion did not change between 18 and 32 weeks of pregnancy. Brisk walking, swimming, and antenatal exercise were the most popular activities reported by British pregnant women.

Previous studies which prospectively followed pregnant women were inconsistent with regard to the changes in physical activity levels during pregnancy. Borodulin et al. reported that the median MET values of the reported activities did not change from 17-22 weeks to 27-30 weeks of gestation while the median duration of reported activities declined slightly between these two time points [40]. A small British study of 57 healthy nulliparous pregnant women reported that the mean physical activity level assessed as MET-hr/day decreased from the second to third trimester during pregnancy [41]. Another Swedish study used both questionnaire and heart rate recording to measure the number of minutes per $24 \mathrm{~h}$ spent in each of six or seven activity categories based on its intensity and type and found little change in physical activity during pregnancy between 14 and 32 weeks of gestation among 23 healthy and nonsmoking women [42]. The differences between studies likely indicate different methods of assessing physical activity as well as the potential differences in study population's characteristics.

Our findings about the most commonly-reported leisure physical activity during pregnancy (i.e., brisk walking and swimming) are consistent with previous studies [32-34, 43]. Consistent with the literature [32, 33, 44, 45], we found that pregnant women of younger ages, compared to older women, were more active during pregnancy. Women who were not employed, those who were married as opposed to single and parous compared with nulliparous women were more active during pregnancy and existing literature on these correlates are not consistent so far [31, 33, 34, 43]. Our results highlight groups who might be targeted for promotion to increase physical activity in pregnancy in UK should evidence emerge that physical activity would be beneficial to them and their developing fetus.

Compared with normal weight women, women who were obese were less likely to participate in brisk walking while they were not different in participating in other types of physical activities. Because brisk walking is the most common leisure time physical activity among pregnant women, future interventions with the goal of increasing physical activity among pregnant women should pay attention to the preferred activity for this high risk population.

It is interesting that educated women were more likely to participate in leisure-time physical activities (including brisk walking and swimming), while they were less likely to report engaging in strenuous physical activity at 32 weeks of gestation. Similarly, we also noticed that women from families in higher social classes were more likely to report swimming, whilst they were less likely to report engaging in strenuous physical activity at 18 and 32 weeks of gestation and more likely to decrease their activity levels since pregnancy. These differences might be related to differential reporting across social groups. It is possible that highly educated women or women from higher social class may have done less household- or occupation-related activities during their pregnancy (which were included in strenuous physical activity), while these 
Table 4 Correlates of levels and self-perceived changes in physical activity during pregnancy, ALSPAC

\begin{tabular}{|c|c|c|c|c|c|c|c|c|c|}
\hline \multirow[t]{2}{*}{ Characteristic } & \multicolumn{3}{|c|}{ Strenuous PA $\geq 3 \mathrm{~h} /$ week $(18 \text { weeks })^{\mathrm{a}}$} & \multicolumn{3}{|c|}{ Strenuous PA $\geq 3 \mathrm{~h} /$ week $(32 \text { weeks })^{\mathrm{a}}$} & \multicolumn{3}{|c|}{$\begin{array}{l}\text { Perceived decrease in activity since } \\
\text { pregnancy }^{\text {a }}\end{array}$} \\
\hline & $\begin{array}{l}\text { Crude OR } \\
(95 \% \mathrm{CI})\end{array}$ & $\begin{array}{l}\mathrm{AOR}^{\mathrm{b}} \\
(95 \% \mathrm{CI})\end{array}$ & $\begin{array}{l}P \text { value } \\
\text { for trend }\end{array}$ & $\begin{array}{l}\text { Crude OR } \\
(95 \% \mathrm{CI})\end{array}$ & $\begin{array}{l}\mathrm{AOR}^{\mathrm{b}} \\
(95 \% \mathrm{CI})\end{array}$ & $\begin{array}{l}P \text { value } \\
\text { for trend }\end{array}$ & $\begin{array}{l}\text { Crude OR } \\
(95 \% \text { CI })\end{array}$ & $\begin{array}{l}\mathrm{AOR}^{\mathrm{b}} \\
(95 \% \mathrm{CI})\end{array}$ & $\begin{array}{l}P \text { value } \\
\text { for trend }\end{array}$ \\
\hline \multicolumn{10}{|l|}{ Age (years) } \\
\hline$\leq 19$ & $1.5(1.1,2.0)$ & $1.6(1.1,2.1)$ & & $2.2(1.6,2.9)$ & $1.9(1.3,2.6)$ & & $0.3(0.2,0.5)$ & $0.3(0.1,0.5)$ & \\
\hline $20-24$ & $1.7(1.4,2.1)$ & $1.7(1.4,2.1)$ & & $2.8(2.3,3.3)$ & $2.5(2.0 .3 .0)$ & & $0.4(0.3,0.5)$ & $0.4(0.3,0.5)$ & \\
\hline $25-29$ & $1.5(1.3,1.8)$ & $1.6(1.3,1.9)$ & & $1.9(1.7,2.3)$ & $1.9(1.6,2.3)$ & & $0.5(0.4,0.6)$ & $0.5(0.4,0.7)$ & \\
\hline $30-34$ & $1.3(1.1,1.5)$ & $1.3(1.1,1.5)$ & $<0.001$ & $1.5(1.2,1.8)$ & $1.5(1.3,1.8)$ & $<0.001$ & $0.7(0.6,0.9)$ & $0.7(0.6,0.9)$ & $<0.001$ \\
\hline$\geq 35$ & Reference & Reference & & Reference & Reference & & Reference & Reference & \\
\hline \multicolumn{10}{|l|}{ Education } \\
\hline A or university & $0.7(0.6,0.8)$ & $0.9(0.8,1.1)$ & & $0.6(0.5,0.6)$ & $0.8(0.7,0.9)$ & & $2.0(1.6,2.5)$ & $1.5(1.1,1.9)$ & \\
\hline O level & $0.9(0.8,1.1)$ & $1.0(0.9,1.2)$ & & $0.8(0.7,0.9)$ & $0.9(0.8,1.0)$ & & $1.3(1.0,1.6)$ & $1.2(0.9,1.6)$ & \\
\hline Vocational & $0.9(0.7,1.1)$ & $0.9(0.8,1.1)$ & & $0.9(0.8 .1 .1)$ & $1.0(0.8,1.2)$ & & $0.9(0.6,1.3)$ & $0.9(0.6,1.2)$ & \\
\hline None or CSE & Reference & Reference & 0.143 & Reference & Reference & 0.001 & Reference & Reference & $<0.001$ \\
\hline \multicolumn{10}{|c|}{ Highest social class of the couple } \\
\hline I & $0.5(0.4,0.6)$ & $0.7(0.5,0.9)$ & & $0.4(0.3,0.6)$ & $0.7(0.5,0.9)$ & & $3.2(2.0,5.2)$ & $2.0(1.2,3.3)$ & \\
\hline II & $0.7(0.6,0.9)$ & $0.9(0.7,1.1)$ & & $0.6(0.5,0.8)$ & $0.9(0.7,1.1)$ & & $2.4(1.5,3.8)$ & $1.7(1.1,2.8)$ & \\
\hline III, Non-manual & $0.8(0.6,1.0)$ & $0.9(0.7,1.1)$ & & $0.7(0.6,0.9)$ & $0.8(0.7,1.1)$ & & $1.7(1.1,2.7)$ & $1.5(0.9,2.5)$ & \\
\hline III, Manual & $1.1(0.8,1.4)$ & $1.1(0.9,1.4)$ & $<0.001$ & $0.9(0.7,1.2)$ & $1.0(0.8,1.2)$ & 0.003 & $1.6(0.9,2.6)$ & $1.5(0.9,2.5)$ & 0.004 \\
\hline IV and $\mathrm{V}$ & Reference & Reference & & Reference & Reference & & Reference & Reference & \\
\hline \multicolumn{10}{|c|}{ Employment at 18 weeks } \\
\hline Not employed & $1.5(1.3,1.6)$ & $1.2(1.1,1.4)$ & & $1.2(1.1,1.4)$ & $1.1(1.0,1.2)$ & & $0.9(0.8,1.0)$ & $1.1(0.9,1.3)$ & \\
\hline Employed & Reference & Reference & & Reference & Reference & & Reference & Reference & \\
\hline \multicolumn{10}{|c|}{ Marital status at 8 weeks } \\
\hline Married & $1.0(0.9 .1 .1)$ & $1.1(1.0,1.3)$ & & $0.9(0.8,1.0)$ & $1.1(1.0,1.3)$ & & $1.0(0.9 .1 .2)$ & $0.9(0.7,1.1)$ & \\
\hline Unmarried & Reference & Reference & & Reference & Reference & & Reference & Reference & \\
\hline \multicolumn{10}{|c|}{ Smoking before pregnancy } \\
\hline No & $0.8(0.7,0.9)$ & $0.8(0.7,0.9)$ & & $0.7(0.6,0.7)$ & $0.7(0.7,0.8)$ & & $1.2(1.0,1.4)$ & $1.0(0.8,1.2)$ & \\
\hline Yes & Reference & Reference & & Reference & Reference & & Reference & Reference & \\
\hline \multicolumn{10}{|l|}{ General health } \\
\hline Always well & $1.0(0.9,1.3)$ & $1.2(0.9,1.4)$ & & $1.0(0.8,1.2)$ & $1.2(0.9,1.4)$ & & $0.6(0.5,0.8)$ & $0.5(0.4,0.7)$ & \\
\hline Usually well & $0.9(0.8,1.1)$ & $0.9(0.8,1.2)$ & $<0.001$ & $0.9(0.7,1.0)$ & $0.9(0.8,1.1)$ & $<0.001$ & $0.7(0.5,0.9)$ & $0.6(0.5,0.8)$ & $<0.001$ \\
\hline Unwell & Reference & Reference & & Reference & Reference & & Reference & Reference & \\
\hline \multicolumn{10}{|l|}{ Pre-pregnancy BMI } \\
\hline Underweight & $1.1(0.9,1.3)$ & $1.0(0.8,1.3)$ & & $0.9(0.8,1.1)$ & $0.8(0.7,1.0)$ & & $1.1(0.8,1.5)$ & $1.2(0.8,1.6)$ & \\
\hline Normal weight & Reference & Reference & & Reference & Reference & & Reference & Reference & \\
\hline Overweight & $1.1(1.0,1.3)$ & $1.1(0.9,1.2)$ & & $1.1(1.0,1.2)$ & $1.0(0.9,1.2)$ & & $0.9(0.7,1.1)$ & $0.9(0.8,1.1)$ & \\
\hline Obese & $1.2(1.0,1.4)$ & $1.1(0.9,1.3)$ & 0.345 & $1.1(0.9,1.4)$ & $1.0(0.8,1.2)$ & 0.359 & $0.7(0.5,0.9)$ & $0.8(0.5,1.1)$ & 0.092 \\
\hline \multicolumn{10}{|l|}{ Previous live births } \\
\hline 0 & Reference & Reference & & Reference & Reference & & Reference & Reference & \\
\hline 1 & $1.4(1.3,1.5)$ & $1.3(1.2,1.5)$ & & $1.1(0.9,1.2)$ & $1.1(1.0,1.2)$ & & $0.8(0.6,0.9)$ & $0.7(0.6,0.8)$ & \\
\hline$\geq 2$ & $1.5(1.3,1.7)$ & $1.4(1.3,1.7)$ & $<0.001$ & $1.1(1.0,1.3)$ & $1.2(1.1,1.4)$ & 0.009 & $0.9(0.8,1.2)$ & $0.8(0.6,1.0)$ & 0.008 \\
\hline
\end{tabular}

AOR adjusted odds ratio, $C I$ confidence interval, $O R$ odds ratio

${ }^{\text {a }}$ Due to additional missing values in outcome variables or covariates included in the models, the analytical sample size for strenuous physical activity at 18 and 32 weeks were 8,136. The sample size for decreased physical activity outcome was 8,097

b Adjusted for all variables listed in the table 
Table 5 Correlates of participating in leisure time physical activity at 18 weeks of gestation, ALSPAC

\begin{tabular}{|c|c|c|c|c|c|c|c|c|c|}
\hline \multirow[t]{2}{*}{ Characteristic } & \multicolumn{3}{|c|}{ Top quintile of weighted activity index ${ }^{a}$} & \multicolumn{3}{|c|}{ Brisk Walking $^{\mathrm{a}}$} & \multicolumn{3}{|l|}{ Swimming $^{\mathrm{a}}$} \\
\hline & $\begin{array}{l}\text { Crude OR } \\
(95 \% \text { CI })\end{array}$ & $\begin{array}{l}\mathrm{AOR}^{\mathrm{b}} \\
(95 \% \mathrm{CI})\end{array}$ & $\begin{array}{l}P \text { value } \\
\text { for trend }\end{array}$ & $\begin{array}{l}\text { Crude OR } \\
(95 \% \text { CI })\end{array}$ & $\begin{array}{l}\mathrm{AOR}^{\mathrm{b}} \\
(95 \% \mathrm{CI})\end{array}$ & $\begin{array}{l}P \text { value } \\
\text { for trend }\end{array}$ & $\begin{array}{l}\text { Crude OR } \\
(95 \% \text { CI })\end{array}$ & $\begin{array}{l}\mathrm{AOR}^{\mathrm{b}} \\
(95 \% \mathrm{CI})\end{array}$ & $\begin{array}{l}P \text { value } \\
\text { for trend }\end{array}$ \\
\hline \multicolumn{10}{|l|}{ Age (years) } \\
\hline$\leq 19$ & $1.3(0.9,1.9)$ & $1.8(1.2,2.7)$ & & $0.9(0.6,1.2)$ & $1.2(0.8,1.7)$ & & $0.7(0.5,1.0)$ & $1.5(1.1,2.1)$ & \\
\hline $20-24$ & $1.0(0.8,1.3)$ & $1.3(1.0,1.7)$ & & $0.9(0.7,1.1)$ & $1.0(0.8,1.3)$ & & $0.8(0.7,1.0)$ & $1.3(1.1,1.6)$ & \\
\hline $25-29$ & $1.1(0.9,1.4)$ & $1.3(1.0,1.6)$ & & $1.1(0.9,1.4)$ & $1.2(1.0,1.4)$ & & $1.1(0.9,1.3)$ & $1.4(1.1,1.5)$ & \\
\hline $30-34$ & $1.2(0.9,1.5)$ & $1.2(1.0,1.6)$ & & $1.3(1.1,1.6)$ & $1.3(1.1,1.6)$ & & $1.2(1.0,1.4)$ & $1.2(1.1,1.5)$ & \\
\hline$\geq 35$ & Reference & Reference & 0.015 & Reference & Reference & 0.664 & Reference & Reference & 0.007 \\
\hline \multicolumn{10}{|l|}{ Education } \\
\hline A or university & $2.2(1.8,2.6)$ & $2.3(1.9,2.9)$ & & $2.1(1.8,2.5)$ & $2.0(1.7,2.4)$ & & $2.4(2.1,2.7)$ & $2.0(1.7,2.4)$ & \\
\hline O level & $1.4(1.1,1.7)$ & $1.5(1.2,1.8)$ & & $1.6(1.4,1.8)$ & $1.5(1.3,1.8)$ & & $1.5(1.3,1.7)$ & $1.4(1.2,1.6)$ & \\
\hline Vocational & $1.1(0.9 .1 .5)$ & $1.1(0.9,1.5)$ & & $1.1(0.9,1.4)$ & $1.1(0.9,1.4)$ & & $1.4(1.1,1.6)$ & $1.3(1.1,1.6)$ & \\
\hline None or CSE & Reference & Reference & $<0.001$ & Reference & Reference & $<0.001$ & Reference & Reference & $<0.001$ \\
\hline \multicolumn{10}{|c|}{ Highest social class of the couple } \\
\hline $\mathrm{I}$ & $1.6(1.2,2.2)$ & $1.1(0.8,1.5)$ & & $1.4(1.1,1.8)$ & $0.8(0.6,1.1)$ & & $2.5(1.9,3.2)$ & $1.7(1.3,2.2)$ & \\
\hline II & $1.4(1.0,1.9)$ & $1.1(0.8,1.5)$ & & $1.2(0.9,1.5)$ & $0.8(0.7,1.1)$ & & $1.8(1.4,2.3)$ & $1.4(1.1,1.8)$ & \\
\hline III, Non-manual & $1.0(0.8,1.4)$ & $1.0(0.7,1.3)$ & & $0.9(0.7,1.2)$ & $0.8(0.6,1.0)$ & & $1.2(1.0,1.6)$ & $1.1(0.9,1.4)$ & \\
\hline III, Manual & $1.2(0.8,1.6)$ & $1.1(0.8,1.5)$ & & $0.9(0.7,1.2)$ & $0.8(0.6,1.1)$ & & $1.1(0.9,1.5)$ & $1.1(0.8,1.4)$ & \\
\hline IV and $\mathrm{V}$ & Reference & Reference & 0.423 & Reference & Reference & 0.585 & Reference & Reference & $<0.001$ \\
\hline \multicolumn{10}{|c|}{ Employment at 18 weeks } \\
\hline Not employed & $1.1(1.0,1.2)$ & $1.2(1.1,1.4)$ & & $1.1(1.0,1.2)$ & $1.3(1.2,1.5)$ & & $0.9(0.9,1.1)$ & $1.0(0.9,1.1)$ & \\
\hline Employed & Reference & Reference & & Reference & Reference & & Reference & Reference & \\
\hline \multicolumn{10}{|c|}{ Marital status at 8 weeks } \\
\hline Married & $0.9(0.8,1.1)$ & $0.8(0.7,1.0)$ & & $1.2(1.1,1.4)$ & $1.1(1.0,1.3)$ & & $1.2(1.1,1.4)$ & $0.9(0.8,1.1)$ & \\
\hline Unmarried & Reference & Reference & & Reference & Reference & & Reference & Reference & \\
\hline \multicolumn{10}{|c|}{ Smoking before pregnancy } \\
\hline No & $1.1(0.9,1.2)$ & $0.9(0.8,1.1)$ & & $1.3(1.1,1.4)$ & $1.1(1.0,1.3)$ & & $1.5(1.3,1.6)$ & $1.2(1.1,1.4)$ & \\
\hline Yes & Reference & Reference & & Reference & Reference & & Reference & Reference & \\
\hline \multicolumn{10}{|l|}{ General health } \\
\hline Always well & $1.5(1.2,1.9)$ & $1.5(1.2,1.9)$ & & $1.6(1.3,1.9)$ & $1.4(1.1,1.7)$ & & $1.3(1.1,1.6)$ & $1.1(0.9,1.4)$ & \\
\hline Usually well & $1.1(0.9,1.4)$ & $1.1(0.8,1.4)$ & & $1.4(1.1,1.7)$ & $1.3(1.0,1.5)$ & & $1.1(0.9,1.3)$ & $1.0(0.8,1.2)$ & \\
\hline Unwell & Reference & Reference & $<0.001$ & Reference & Reference & 0.004 & Reference & Reference & 0.037 \\
\hline \multicolumn{10}{|l|}{ Pre-pregnancy BMI } \\
\hline Underweight & $1.0(0.7,1.3)$ & $1.0(0.8,1.3)$ & & $0.9(0.7,1.2)$ & $1.0(0.8,1.3)$ & & $0.8(0.6,1.0)$ & $0.9(0.7,1.1)$ & \\
\hline Normal weight & Reference & Reference & & Reference & Reference & & Reference & Reference & \\
\hline Overweight & $0.9(0.8,1.1)$ & $1.1(0.9,1.2)$ & & $0.8(0.7,0.9)$ & $0.9(0.8,1.0)$ & & $1.0(0.9,1.1)$ & $1.1(1.0,1.2)$ & \\
\hline Obese & $0.8(0.6,1.1)$ & $1.0(0.8,1.3)$ & 0.647 & $0.7(0.5,0.8)$ & $0.8(0.6,0.9)$ & 0.004 & $0.7(0.6,0.9)$ & $0.9(0.7,1.1)$ & 0.779 \\
\hline \multicolumn{10}{|l|}{ Previous live births } \\
\hline 0 & Reference & Reference & & Reference & Reference & & Reference & Reference & \\
\hline 1 & $1.0(0.9,1.1)$ & $1.0(0.9,1.2)$ & & $1.0(0.9,1.1)$ & $0.9(0.8,1.0)$ & & $1.3(1.2,1.5)$ & $1.4(1.3,1.6)$ & \\
\hline$\geq 2$ & $0.9(0.8,1.0)$ & $1.0(0.8,1.2)$ & 0.868 & $0.9(0.8,1.0)$ & $0.8(0.7,1.0)$ & 0.036 & $1.0(0.9,1.1)$ & $1.2(1.0,1.4)$ & $<0.001$ \\
\hline
\end{tabular}

CI confidence interval, $A O R$ adjusted odds ratio

${ }^{a}$ Due to additional missing values in outcome variables or covariates included in the models, the analytical sample size for weighted activity index $=8,135$, brisk walking $=8,055$, swimming $=8,003$

b All models adjusted for all variables listed in the table

women were more likely to spend time on leisure-time physical activities such as swimming. It is also possible that women from higher socioeconomic groups do perform less physical activity in pregnancy of all types because we found that women in these groups were more likely to report reducing their levels of physical activity when they 
found out that they had become pregnant. Thus, these findings should be interpreted with caution.

Some limitations of this study warrant consideration. First, our physical activity measures were self-reported and thus prone to misclassification. In particular using reports of activities that result in sweating as an indicator of strenuous activity might not provide an accurate measure of prevalence for strenuous activity because sweating will be influenced by other characteristics, such as the participant's general fitness, BMI, as well as the actual level of activity. However, very few general population studies with large number exist that have used objective measures of physical activity. Second, household/caregiving activities and occupational activities each contribute to $25 \%$ of the total activity for pregnant women, the same amount for recreational activities [40]. ALSPAC only included minimum information on household/caregiving (examples like gardening and homework) in the strenuous physical activity questions and had no information on occupational activities. Because of this, our weighted activity index was based on total energy expenditure from leisure time physical activities instead of all types of activities. With 11 common leisure-time exercises being listed in the questions plus "other" category, our weighted activity index may underreport the total leisure time physical activities. Third, the repeated measure of physical activity was limited because the complete information on the types and levels of leisure-time physical activity were only collected at 18 weeks but not 32 weeks of gestation. Fourth, $30 \%$ of women were excluded from our analyses mostly due to no responses to the specific questionnaires and partially due to missing values in physical activity variables. The excluded women were more likely to be younger, from lower socioeconomic position, unmarried, to be smokers, in poorer health, and parous. When we compared crude odds ratios between those with complete data (included in the main analyses) and those eligible with maximum data the results were very similar suggesting that these differences have not introduced important selection bias. Finally, we used the data collected in 1991-1992 when women were recruited into ALSPAC in the areas adjacent to the city of Bristol when obesity was not as prevalent as today [46-48]. Thus, the findings may not be generalized to other populations and to more recent time periods.

In spite of these limitations, our study is unique because we used the data from a large population-based prospective cohort with physical activity assessed by questionnaires at 18 and 32 weeks of gestation. This adds to the literature where only a few small pilot studies examined physical activity among British pregnant women $[41,49]$ and there is no population-based British study on physical activity during pregnancy. Our result that partner's physical activity is positively associated with women's physical activity levels during pregnancy is consistent with existing literature among non-pregnant populations [36, 37].

Our findings provide some insights into the design of programs aimed at promoting physical activity among pregnant women in terms of the types of leisure-time physical activities (e.g., walking, swimming, and antenatal classes) that women preferred and subgroups to be targeted for future interventions in terms of promoting physical activity among healthy pregnant women. Our study highlights some of the key potential confounding factors that should be considered in future studies examining the relationship of physical activity in pregnancy with outcomes in mothers and offspring. It also notes some interesting and unanticipated correlations. Notably women who were more educated and of higher social classes were less likely to participate in strenuous physical activity than those of lower social groups while they were more likely to report leisuretime physical activity. By contrast many adverse perinatal outcomes, including low birth weight and preterm birth are less common in women from higher social groups (with smoking being a strong mediator of these associations) [50]. Thus, studies exploring the association of physical activity and perinatal outcomes, inadequate control for socioeconomic position may mask a stronger than observed association between physical activity and these outcomes.

Acknowledgments The UK Medical Research Council, the Wellcome Trust, and the University of Bristol provide core support for ALSPAC. Dr. Lawlor's contribution to this work was funded by National Institute of Diabetes and Digestive and Kidney Disease grant (R01 DK077659). Drs. Blair, Ness, Riddoch's contribution to this work was funded by National Institute of Heart, Lung, and Blood Institute grant (R01 HL071248-01A). We are extremely grateful to all the families who took part in this study, the midwives for their help in recruiting them, and the whole ALSPAC team, which includes interviewers, computer and laboratory technicians, clerical workers, research scientists, volunteers, managers, receptionists and nurses.

\section{References}

1. Haskell WL, Lee IM, Pate RR, et al. Physical activity and public health: updated recommendation for adults from the american college of sports medicine and the american heart association. Circulation. 2007;116:1081-93.

2. Nelson ME, Rejeski WJ, Blair SN, et al. Physical activity and public health in older adults: recommendation from the american college of sports medicine and the american heart association. Circulation. 2007;116:1094-105.

3. Steptoe A, Butler N. Sports participation and emotional wellbeing in adolescents. Lancet. 1996;347:1789-92.

4. Pivarnik JM, Chambliss HO, Clapp JF III, et al. Impact of physical activity during pregnancy and postpartum on chronic disease risk. Med Sci Sports Exerc. 2006;38:989-1006.

5. Dempsey JC, Butler CL, Sorensen TK, et al. A case-control study of maternal recreational physical activity and risk of gestational diabetes mellitus. Diabetes Res Clin Pract. 2004;66:203-15. 
6. Dempsey JC, Butler CL, Williams MA. No need for a pregnant pause: physical activity may reduce the occurrence of gestational diabetes mellitus and preeclampsia. Exerc Sport Sci Rev. 2005;33: 141-9.

7. Dempsey JC, Sorensen TK, Williams MA, et al. Prospective study of gestational diabetes mellitus risk in relation to maternal recreational physical activity before and during pregnancy. Am J Epidemiol. 2004;159:663-70.

8. Dye TD, Knox KL, Artal R, et al. Physical activity, obesity, and diabetes in pregnancy. Am J Epidemiol. 1997;146:961-5.

9. Solomon CG, Willett WC, Carey VJ, et al. A prospective study of pregravid determinants of gestational diabetes mellitus. Jama. 1997;278:1078-83.

10. Zhang C, Solomon CG, Manson JE, et al. A prospective study of pregravid physical activity and sedentary behaviors in relation to the risk for gestational diabetes mellitus. Arch Intern Med. 2006; 166:543-8.

11. Liu J, Laditka JN, Mayer-Davis E, et al. Does physical activity during pregnancy reduce risk of gestational diabetes among previously inactive women. Birth. 2008;35:189-96.

12. Rudra CB, Williams MA, Lee IM, et al. Perceived exertion during prepregnancy physical activity and preeclampsia risk. Med Sci Sports Exerc. 2005;37:1836-41.

13. Saftlas AF, Logsden-Sackett N, Wang W, et al. Work, leisuretime physical activity, and risk of preeclampsia and gestational hypertension. Am J Epidemiol. 2004;160:758-65.

14. Sorensen TK, Williams MA, Lee IM, et al. Recreational physical activity during pregnancy and risk of preeclampsia. Hypertension. 2003;41:1273-80. (Epub 2003 Apr 28).

15. Magnus P, Trogstad L, Owe KM, et al. Recreational physical activity and the risk of preeclampsia: a prospective cohort of Norwegian women. Am J Epidemiol. 2008;168:952-7.

16. Rudra CB, Sorensen TK, Luthy DA, et al. A prospective analysis of recreational physical activity and preeclampsia risk. Med Sci Sports Exerc. 2008;40(9):1581-8.

17. Latka M, Kline J, Hatch M. Exercise and spontaneous abortion of known karyotype. Epidemiology. 1999;10:73-5.

18. Hjollund NH, Jensen TK, Bonde JP, et al. Spontaneous abortion and physical strain around implantation: a follow-up study of first-pregnancy planners. Epidemiology. 2000;11:18-23.

19. Madsen M, Jorgensen T, Jensen ML, et al. Leisure time physical exercise during pregnancy and the risk of miscarriage: a study within the danish national birth cohort. Bjog. 2007;114:1419-26.

20. Clapp JF 3rd. The effects of maternal exercise on early pregnancy outcome. Am J Obstet Gynecol. 1989;161:1453-7.

21. Magann EF, Evans SF, Weitz B, et al. Antepartum, intrapartum, and neonatal significance of exercise on healthy low-risk pregnant working women. Obstet Gynecol. 2002;99:466-72.

22. Rose NC, Haddow JE, Palomaki GE, et al. Self-rated physical activity level during the second trimester and pregnancy outcome. Obstet Gynecol. 1991;78:1078-80.

23. Kramer MS, McDonald SW. Aerobic exercise for women during pregnancy. Cochrane Database Syst Rev. 2006;3:CD000180.

24. American College of Obstetricians and Gynecologists. Exercise during pregnancy and the postpartum period. ACOG Committee opinion 267. Obstet Gynecol. 2002;99:171-3.

25. Davies GA, Wolfe LA, Mottola MF, et al. Joint SOGC/CSEP clinical practice guideline: exercise in pregnancy and the postpartum period. Can J Appl Physiol. 2003;28:330-41.

26. Royal College of Obstetricians and Gynecologists (RCOG). Exercise in pregnancy. RCOG Statement No. 4. January 2006, 1-7. URL: http:// www.rcog.org.uk/files/rcog-corp/uploaded-files/RCOGStatement4 ExercisePregnancy2006.pdf. Accessed 21 Dec 2010.

27. Juhl M, Andersen PK, Olsen J, et al. Physical exercise during pregnancy and the risk of preterm birth: a study within the danish national birth cohort. Am J Epidemiol. 2008;167:859-66.
28. Golding J, Pembrey M, Jones R. ALSPAC-the Avon Longitudinal Study of Parents and Children. I Study methodology. Paediatr Perinat Epidemiol. 2001;15:74-87.

29. Wildschut HI, Harker LM, Riddoch CJ. The potential value of a short self-completion questionnaire for the assessment of habitual physical activity in pregnancy. J Psychosom Obstet Gynaecol. 1993;14:17-29.

30. Ainsworth BE, Haskell WL, Whitt MC, et al. Compendium of physical activities: an update of activity codes and MET intensities. Med Sci Sports Exerc. 2000;32:S498-504.

31. Chasan-Taber L, Schmidt MD, Pekow P, et al. Correlates of physical activity in pregnancy among Latina women. Matern Child Health J. 2007;11:353-63.

32. Evenson KR, Savitz DA, Huston SL. Leisure-time physical activity among pregnant women in the US. Paediatr Perinat Epidemiol. 2004;18:400-7.

33. Ning Y, Williams MA, Dempsey JC, et al. Correlates of recreational physical activity in early pregnancy. J Matern Fetal Neonatal Med. 2003;13:385-93.

34. Zhang J, Savitz DA. Exercise during pregnancy among US women. Ann Epidemiol. 1996;6:53-9.

35. Office of Population Censuses and Surveys. Standard occupational classification. London: HMSO; 1991.

36. Pettee KK, Brach JS, Kriska AM, et al. Influence of marital status on physical activity levels among older adults. Med Sci Sports Exerc. 2006;38:541-6.

37. Satariano WA, Haight TJ, Tager IB. Living arrangements and participation in leisure-time physical activities in an older population. J Aging Health. 2002;14:427-51.

38. Keefe TJ. On the relationship between two tests for homogeneity of the marginal distributions in a two-way classification. Biometrika. 1982;69:683-4.

39. Bhapkar VP. On the analysis of contingency tables with a quantitative response. Biometrics. 1968;24:329-38.

40. Borodulin KM, Evenson KR, Wen F, et al. Physical activity patterns during pregnancy. Med Sci Sports Exerc. 2008;40(11):1901-8.

41. Rousham EK, Clarke PE, Gross H. Significant changes in physical activity among pregnant women in the UK as assessed by accelerometry and self-reported activity. Eur J Clin Nutr. 2006;60:393-400.

42. Lof M, Forsum E. Activity pattern and energy expenditure due to physical activity before and during pregnancy in healthy Swedish women. Br J Nutr. 2006;95:296-302.

43. Pereira MA, Rifas-Shiman SL, Kleinman KP, et al. Predictors of change in physical activity during and after pregnancy: project Viva. Am J Prev Med. 2007;32:312-9.

44. Petersen AM, Leet TL, Brownson RC. Correlates of physical activity among pregnant women in the United States. Med Sci Sports Exerc. 2005;37:1748-53.

45. Fell DB, Joseph KS, Armson BA, et al. The Impact of Pregnancy on Physical Activity Level. Matern Child Health J. 2009;13(5):597-603.

46. Heslehurst N, Rankin J, Wilkinson JR, et al. A nationally representative study of maternal obesity in England, UK: trends in incidence and demographic inequalities in 619323 births, 1989-2007. Int J Obes (Lond). 2010;34:420-8.

47. Guelinckx I, Devlieger R, Beckers K, et al. Maternal obesity: pregnancy complications, gestational weight gain and nutrition. Obes Rev. 2008;9:140-50.

48. British Heart Foundation. Prevalence of obesity by sex, adults aged 16-64 years, 1995-2004. England and Scotland, 2004. URL:http:// www/heartstats.org/datapage.asp?id=1011. Accessed 8 July 2010.

49. Clarke PE, Rousham EK, Gross H, et al. Activity patterns and time allocation during pregnancy: a longitudinal study of British women. Ann Hum Biol. 2005;32:247-58.

50. Kramer MS. Socioeconomic determinants of intrauterine growth retardation. Eur J Clin Nutr. 1998;52(Suppl 1):S29-32. (discussion S-3). 